\title{
Factors associated with four atypical cases of congenital syphilis in England, 2016 to 2017: an ecological analysis
}

Martina Furegato ${ }^{1}$, Helen Fifer ${ }^{2}$, Hamish Mohammed ${ }^{1}$, Ian Simms ${ }^{1}$, Paul Vanta $^{1}$, Sharon Webb ${ }^{3}$, Kirsty Foster ${ }^{1}$, Margaret

Kingston ${ }^{4}$, André Charlett ${ }^{5}$, Bhavita Vishram ${ }^{6}$, Claire Reynolds ${ }^{6}$, Noel Gill ${ }^{1}$, Gwenda Hughes ${ }^{1}$

1. HIV \& STI Department, Public Health England, Colindale, London, United Kingdom

2. Bacteriology Reference Department, National Infection Service, Public Health England, Colindale, London, United Kingdom

3. NHS Infectious Diseases in Pregnancy Screening Programme, PHE Screening, London, United Kingdom

4. The Northern Integrated Contraception, Sexual Health \& HIV Service, Manchester University NHS Foundation Trust, Manchester, United Kingdom

5. Statistics, Modelling and Economics Department, National Infection Service, Public Health England, Colindale, London, United Kingdom

6. NHS Blood \& Transplant/PHE Epidemiology Unit, Public Health England, Colindale, London, United Kingdom

Correspondence: Ian Simms (ian.simms@phe.gov.uk)

Citation style for this article:

Furegato Martina, Fifer Helen, Mohammed Hamish, Simms lan, Vanta Paul, Webb Sharon, Foster Kirsty, Kingston Margaret, Charlett André, Vishram Bhavita,

Reynolds Claire, Gill Noel, Hughes Gwenda. Factors associated with four atypical cases of congenital syphilis in England, 2016 to 2017 : an ecological analysis. Euro Surveill. 2017;22(49):pii=17-00750. https://doi.org/10.2807/1560-7917.ES.2017.22.49.17-00750

Four isolated cases of congenital syphilis born to mothers who screened syphilis negative in the first trimester were identified between March 2016 and January 2017 compared with three cases between 2010 and 2015. The mothers were United Kingdom-born and had no syphilis risk factors. Cases occurred in areas with recent increases in sexually-transmitted syphilis among women and men who have sex with men, some behaviourally bisexual, which may have facilitated bridging between sexual networks.

Since 2011, the rapid increase in sexually transmitted infectious syphilis (ST-syphilis) (primary, secondary and early latent) diagnoses among gay, bisexual or other men-who-have-sex-with-men (MSM) in England has contrasted with a low, relatively stable number among heterosexuals $[1,2]$. Congenital syphilis (CS) is rare in England with only 21 cases occurring between February 2011 and January 2017 (data not shown) and [3]. Cases have been associated with mothers who were socially marginalised and encountered barriers when accessing antenatal care. Between March 2016 and January 2017 inclusive, we identified four apparently atypical CS cases that were caused by incident maternal syphilis infection after a negative first trimester antenatal screen. We set out to investigate whether this was an unusual event and if there was a spatiotemporal relationship between the epidemiology of ST-syphilis and the recent CS cases to inform the development of a targeted public health response.

\section{Data sources and analyses}

Data were obtained from reports of CS made to Public Health England (PHE) National Infection Service; diagnoses of infectious syphilis reported to the genitourinary medicine clinic activity dataset (GUMCAD) sexually transmitted infections (STI) surveillance system, and mid-year population estimates for England [4,5]. Three analyses were undertaken: simulation modelling with 100,000 simulations based on a Poisson distribution of CS cases reported since 2010; time-series analyses (TSA) were used to identify exceedances in ST-syphilis case-frequencies by sex, sexual orientation and area for the period from January 2011 to September 2016 [6]. The 152 English upper-tier local authorities (LA) were categorised into one of following syphilis epidemiological areas (SEA): (i) incident areas: LAs where the mothers of the CS cases lived; (ii) endemic areas: LAs with established spatiotemporal clusters of ST-syphilis in men [6]; (iii) rest of England: all other LAs in England.

Pearson's chi-squared and Kruskal-Wallis tests were used to compare behavioural and demographic characteristics of ST-syphilis cases across SEAs. To avoid circular analysis bias the mothers of the CS cases were removed from the denominator.

\section{Case characteristics}

The four CS cases were considered unusual because their mothers had screened negative in early pregnancy. The screening used treponemal total antibody ( $\mathrm{gG} / \mathrm{IgM})$ tests. In the subsequent investigation of all four cases, the stored early screening samples, together with maternal samples taken at the time of the CS diagnoses, were tested at the PHE national Reference laboratory using a treponemal total antibody enzyme immunoassay (EIA), IgM specific EIA, Treponema pallidum particle agglutination and Rapid Plasma Reagin tests. It was confirmed that maternal syphilis had been acquired at some point during pregnancy, after 


\section{FIGURE 1}

Congenital syphilis cases by month and year of birth and result of first trimester screening, England, February 2010January $2017(n=21)$

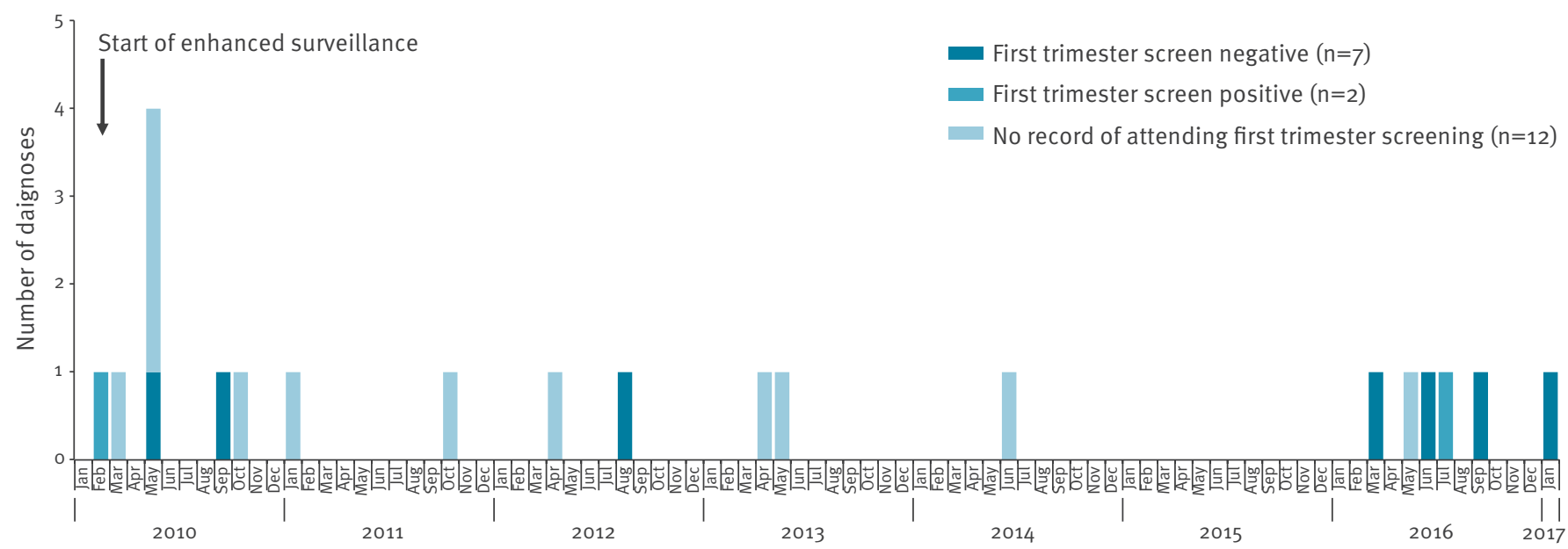

Cases were defined as confirmed following [3].

\section{FIGURE 2}

Time trend and time series analysis model for sexually transmitted infectious syphilis diagnoses by sexual orientation and syphilis epidemiological areas, England, January 2011-September 2016

\section{A. Incident areas}

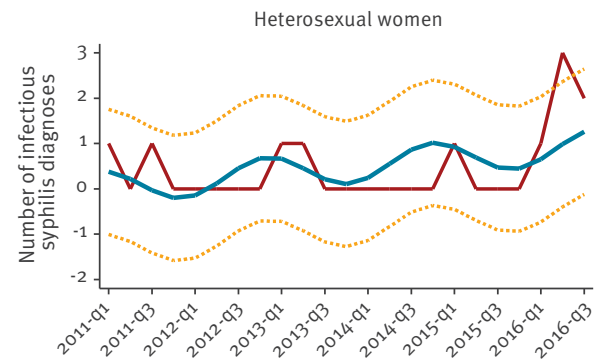

Year and quarter

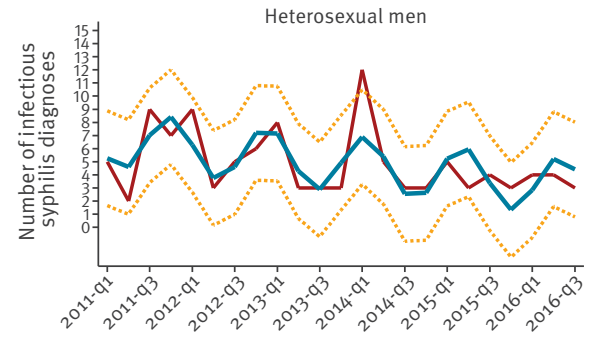

Year and quarter

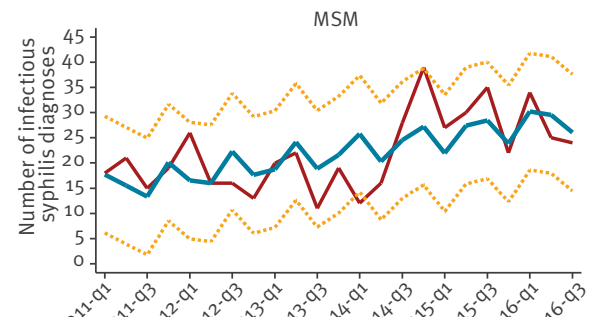

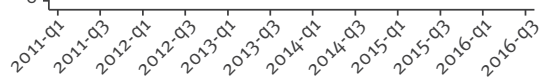

Year and quarter
B. Endemic areas

Heterosexual women

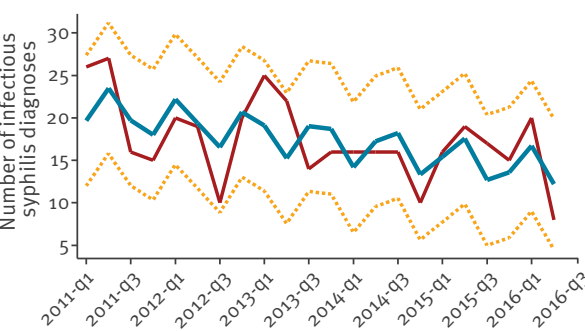

Year and quarter

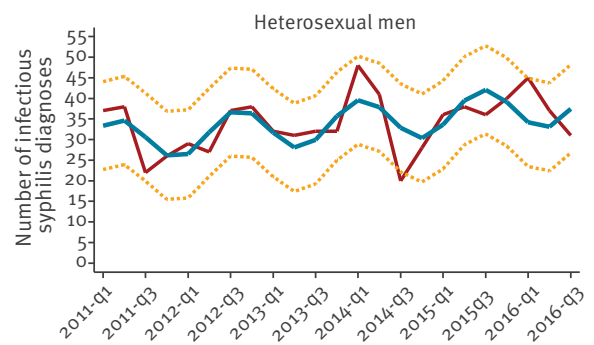

Year and quarter

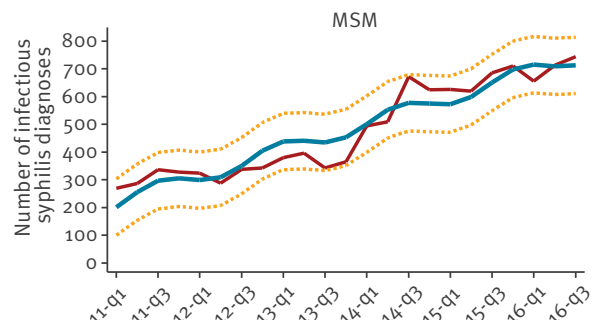

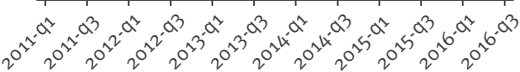

Year and quarter
C. Rest of England

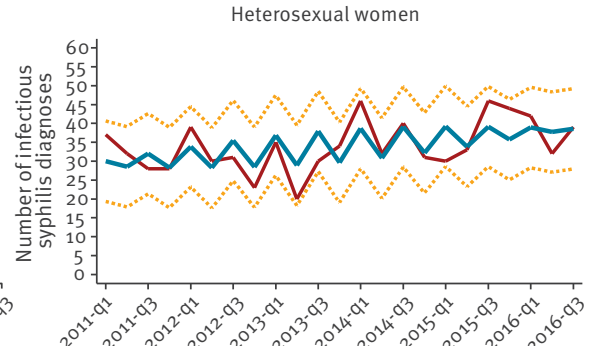

Year and quarter

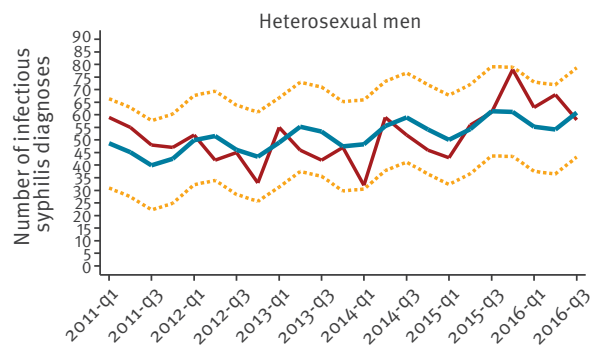

Year and quarter

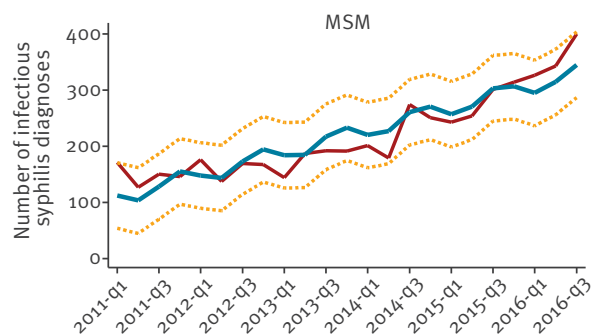

Year and quarter

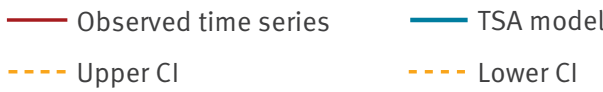

$\mathrm{Cl}$ : 95\% confidence interval; TSA: time series analysis. 
negative early screening. No syphilis risk factors were identified by their physicians at the time of screening. For two cases, our investigations identified social vulnerabilities that had been highlighted in previous studies [3]. All four mothers were white and born in the United Kingdom (UK).

Two infants were classified as confirmed cases of CS (PCR-positive) following the European Union case definition [7]. The remaining two were classified as probable cases because it was likely that the infants' antibody responses had been attenuated due to late acquisition of maternal syphilis and early antibiotic treatment.

Since 2010 there have been 21 CS cases reported in England. Nine of these mothers had a record of antenatal screening of whom seven (including the 4 recent cases) had screened negative at their first trimester antenatal screen (Figure 1) [3]. The probability of observing four CS cases born to screen-negative mothers ('screen-negative' cases) in a 10-month period was estimated to be less than $1 \%$.

\section{Spatiotemporal variation}

From January 2011 to December 2016, ST-syphilis diagnosis rates (per 100,000 population) in incident areas in England, increased by $130 \%$ from 1.1 to 2.3 , in heterosexual women and by $52 \%$ from 8.9 to 15.5 , in MSM, but fell by $37 \%$ from 4.3 to 2.1 , in heterosexual men. In endemic areas, rates fell by $42 \%$ from 3.6 to 2.1 , in heterosexual women, but rose by $131 \%$ from 37.6 to 86.8 ) in MSM and by $21 \%$ ( 5.2 to 6.3) in heterosexual men. In the rest of the country, rates rose by $19 \%$ from 1.6 to 1.9 in heterosexual women, by $138 \%$ from 5.0 to 11.9 in MSM and by $18 \%$ from 2.7 to 3.2 in heterosexual men.

Between March 2016 and January 2017, the number of ST-syphilis cases in heterosexual women significantly exceeded the upper confidence interval in the incident areas (Figure 2). No other exceedance in ST-syphilis cases was identified either for the other population groups or other geographic areas analysed.

In 2016, the proportion of heterosexual women diagnosed with ST-syphilis who were UK-born was greater in the incident areas (2/3) and in the rest of the country (98/120) compared with the endemic areas (13/37; $p<0.001)$. The proportion of MSM diagnosed with ST-syphilis who were behaviourally bisexual was greater in the incident areas (4/29) compared with endemic areas $(11 / 2,113)$ and the rest of England (106/1,122; $p<0.001)$.

\section{Discussion}

Our ecological analyses cannot be used to infer the mothers' risk factors in the specific cases analysed here. Nevertheless, while numbers were small, the rapid increase in syphilis cases in women and MSM and the relatively high proportion of behaviourally bisexual MSM suggest there may have been increased opportunities for transmission between sexual networks in the incident areas.

Syphilis remains rare in the general population: population-based blood donation data show that between 2012 and 2016, the rate of recent syphilis infection in the UK was 1.1 per 100,000 donations from men and 0.5 per 100,000 donations from women [8]. Low rates of CS are also seen in many other European countries which suggest that most have programmes that aim to eliminate CS [9]. The incidence of CS in the UK remains below the World Health Organization (WHO) elimination threshold $(\leq 0.5 / 1,000)$ and the measures of health service provision recommended by WHO have been achieved $[3,10]$. Nevertheless, the recent cases highlight the continuing clinical and social significance of this rare but important disease. CS is preventable through screening and treatment of pregnant women with a single injection of benzathine benzylpenicillin $[10,11]$. However, creating a strategy to eliminate mother-to-child transmission is challenging in the face of the rising syphilis incidence within the population. Uptake of antenatal syphilis screening in England is high at $97 \%$ [3]. Guidelines recommend that women identified as being at risk be re-screened in the third trimester [12]. However, as shown here, it can be difficult to identify those at risk and routine third trimester screening is unlikely to be cost-effective [13].

Maintaining the integrity of clinical care pathways to ensure timely treatment, management and partner notification of identified cases is therefore crucial, and should be subject to regular review [14-16]. Reviewing the performance of these pathways together with clinical outcomes will form part of a new Infectious Disease in Pregnancy Screening Integrated Outcomes System of Maternal and Paediatric Surveillance that is being extended to include syphilis in 2018 [17].

These CS cases emphasise the need for women to be aware of maintaining their sexual health throughout pregnancy. Midwives and other key healthcare professionals play an important role in raising awareness among mothers and their partners to sexual health throughout pregnancy. To support this, the English National Infectious Diseases in Pregnancy Screening Programme is developing media and resources including a bespoke professional e-learning package; 'inconsultation' counselling resource with guidance for practitioners, updated midwifery resource cards and information leaflets for screen-positive women $[18,19]$.

Since the re-emergence of ST-syphilis at the beginning of the century the epidemic has been focused on MSM. Controlling syphilis in MSM and the spread to other population groups is a public health priority. Efforts should be multi-factorial, including risk reduction behavioural interventions as well as improving syphilis testing coverage and frequency in those at greatest risk, including HIV-positive MSM. 


\section{Acknowledgements}

We would like to thank the Public Health England (PHE) Congenital Syphilis incident team. Our thanks also go to the GUMCAD team, HIV and STI Department, PHE, to the Bacteriology Reference Department at PHE, to the Field Epidemiology Service team at PHE.

\section{Conflict of interest}

None declared.

\section{Authors' contributions}

MF conducted the analyses; $A C$ contributed towards the analyses; MF, HM, IS, PV, HF and GH wrote the first draft of the manuscript. All authors contributed towards the study design, interpretation of the data, iterations of the paper and approved the final version of the paper submitted for publication.

\section{References}

1. Mohammed H, Mitchell H, Sile B, Duffell S, Nardone A, Hughes G. Increase in Sexually Transmitted Infections among Men Who Have Sex with Men, England, 2014. Emerg Infect Dis. 2016;22(1):88-91. https://doi.org/10.3201/eid2201.151331 PMID: 26689861

2. Public Health England (PHE). Sexually transmitted infections and chlamydia screening in England, 2016. Health Protection Report. 9 Jun 2017. Available from: https://www.gov.uk/ government/uploads/system/uploads/attachment_data/ file/617025/Health_Protection_Report_STIs_NCSP_2017.pdf

3. Simms I, Tookey PA, Goh BT, Lyall H, Evans B, Townsend CL, et al. The incidence of congenital syphilis in the United Kingdom: February 2010 to January 2015. BJOG. 2017;124(1):72-7. https:// doi.org/10.1111/1471-0528.13950 PMID: 26931054

4. Savage EJ, Mohammed H, Leong G, Duffell S, Hughes G. Improving surveillance of sexually transmitted infections using mandatory electronic clinical reporting: the genitourinary medicine clinic activity dataset, England, 2009 to 2013. Euro Surveill. 2014;19(48):20981. https://doi.org/10.2807/15607917.ES2014.19.48.20981 PMID: 25496573

5. Office for National Statistics (ONS). Population Estimates for UK, England and Wales, Scotland and Northern Ireland: mid-2016. London: ONS. 22 Jun 2017. Available from: https://www.ons.gov.uk/peoplepopulationandcommunity/ populationandmigration/populationestimates/bulletins/ annualmidyearpopulationestimates/latest

6. Petersen J, Gibin M, Sile B, Simms I. Identifying and interpreting spatiotemporal variation in diagnoses of infectious syphilis among men, England: 2009 to 2013. Sex Transm Infect. 2016;92(5):380-6. https://doi.org/10.1136/ sextrans-2015-052306 PMID: 27147614

7. European Commission. Commission Implementing Decision 2012/506/EU of 8 August 2012 amending Decision 2002/253/ EC laying down case definitions for reporting communicable diseases to the Community network under Decision No 2119/98/EC of the European Parliament and of the Council. Luxembourg: Official Journal of the European Union; L262/1. Available from: http://eur-lex.europa.eu/LexUriServ/ LexUriServ.do?uri=0):L:2012:262:0001:0057:EN:PDF

8. Public Health England (PHE). Annual Review of infections in UK blood, tissue and organ donors: 2016. Health Protection Report 2017;11(33). Available from: https://www.gov.uk/government/ publications/health-protection-report-volume-11-2017/ hpr-volume-11-issue-33-news-22-september

9. European Centre for Disease Prevention and Control (ECDC). Congenital syphilis - Annual Epidemiological Report 2016. 2014 data. Stockholm: ECDC. [Accessed 5 Dec 2017]. Available from: https://ecdc.europa.eu/sites/portal/files/documents/ Congenital\%20syphilis\%20AER.pdf

10. World Health Organization (WHO). Global guidance on criteria and processes for validation. Elimination of mother-to-child transmission (EMTCT) of HIV and syphilis. Geneva: WHO; Jun 2014. Available from: http://www.who.int/reproductivehealth/ publications/rtis/9789241505888/en/index.html.

11. World Health Organization (WHO). WHO guideline on syphilis screening and treatment for pregnant women. Geneva: WHO;
2017. Available from: http://www.who.int/reproductivehealth/ publications/rtis/syphilis-ANC-screenandtreat-guidelines/en/

12. Public Health England (PHE). NHS Infectious Diseases in Pregnancy Screening Programme Handbook 2016 to 2017. London: PHE; 2016. Available from: https://www.gov.uk/ government/uploads/system/uploads/attachment_data/ file/542492/NHS_IDPS_Programme_Handbook_2016_to_2017. pdf

13. Albright CM, Emerson JB, Werner EF, Hughes BL. ThirdTrimester Prenatal Syphilis Screening: A Cost-Effectiveness Analysis. Obstet Gynecol. 2015;126(3):479-85. https://doi. org/10.1097/AOG.0000000000000997 PMID: 26244531

14. Hussey J, Mitchell L, Hew Y, Foster K, Waldram A. Preventing congenital syphilis - a regional audit of syphilis in pregnant women seen in Genitourinary Medicine services. Int I STD AIDS 2014;25(6):448-51. https://doi.org/10.1177/0956462413512802 PMID: 24285598

15. Howe B, Basta M, Foster K, Esen U, Ellis R, Hussey J. Primary syphilis in pregnancy mistaken for genital herpes: $A$ preventable cause of congenital syphilis. Eur J Obstet Gynecol Reprod Biol. 2017;219:133. . Available from: https://doi. org/10.1016/j.ejogrb.2017.10.014 https://doi.org/10.1016/j. ejogrb.2017.10.014 PMID: 29103618

16. Dallé J, Baumgarten VZ, Ramos MC, Jimenez MF, Acosta L, Bumaguin DB, et al. Maternal syphilis and accomplishing sexual partner treatment: still a huge gap. Int J STD AIDS. 2017;28(9):876-80. https://doi. org/10.1177/0956462416678710 PMID: 27810981

17. Public Health England (PHE). Infectious diseases in pregnancy screening: programme overview. London: PHE; 1 Apr 2016. Available from: https://www.gov.uk/guidance/infectiousdiseases-in-pregnancy-screening-programme-overview

18. Public Health England (PHE). NHS infectious diseases in pregnancy screening (IDPS) programme. London: PHE. [Accessed 5 Dec 2017. Available from: https:// www.gov.uk/topic/population-screening-programmes/ infectious-diseases-in-pregnancy

19. National Health Service. Continuing Professional Development for Screening. London: Public Health England. [Accessed 5 Dec 2017]. Available from: https://cpdscreening.phe.org.uk/ resource-cards.

\section{License and copyright}

This is an open-access article distributed under the terms of the Creative Commons Attribution (CC BY 4.0) Licence. You may share and adapt the material, but must give appropriate credit to the source, provide a link to the licence, and indicate if changes were made.

This article is copyright of the authors, 2017. 